\title{
Correction to: A new metric of consensus for Likert-type scale questionnaires: an application to consumer expectations
}

\author{
Oscar Claveria ${ }^{1}$ iD
}

Published online: 30 April 2021

(c) Institute for Development and Research in Banking Technology 2021

Correction to: Journal of Banking and Financial Technology https://doi.org/10.1007/s42786-021-00026-5

Unfortunately, Fig. 2 has been published incorrect. Please find the corrected Fig. 2 below:

The typesetter apologizes for this mistake.

The original article was updated.

The original article can be found online at https://doi.org/10.1007/ s42786-021-00026-5.

Oscar Claveria

oclaveria@ub.edu

1 AQR-IREA, University of Barcelona (UB), Diagonal, 690, 08034 Barcelona, Spain 

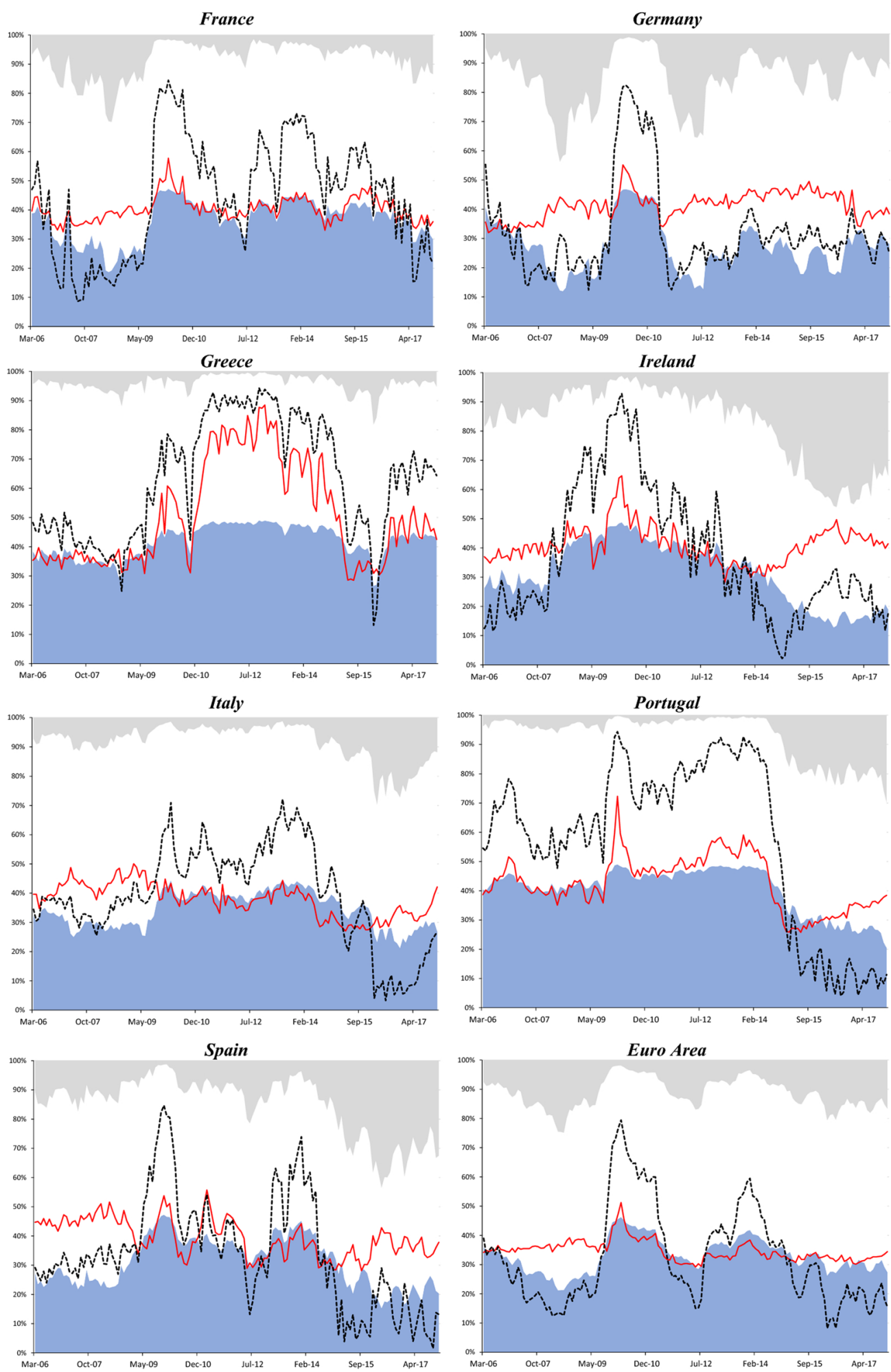

Note: The blue area represents the evolution of the percentage of "fall" responses (sharply and slightly) regarding the level of unemployment over the next 12 months, while the light grey area represents the $\%$ of "increase" responses (sharply and slightly) and the white area the \% of "remain the same (no-change)" responses. The black dashed line represents the evolution of the of the consensus measure for three categories, while the red line the consensus for five categories.

Fig. 2 Consensus metrics and distribution of survey responses by category 